\title{
Improving the world's health through the post-2015 development agenda: perspectives from Rwanda
}

\author{
Agnes Binagwaho ${ }^{1,2,3^{*}}$, Kirstin W Scott ${ }^{4}$
}

\begin{abstract}
The world has made a great deal of progress through the Millennium Development Goals (MDGs) to improve the health and well-being of people around the globe, but there remains a long way to go. Here we provide reflections on Rwanda's experience in working to meet the health-related targets of the MDGs. This experience has informed our proposal of five guiding principles that may be useful for countries to consider as the world sets and moves forward with the post-2015 development agenda. These include: 1) advancing concrete and meaningful equity agendas that drive the post-2015 goals; 2) ensuring that goals to meet Universal Health Coverage (UHC) incorporate real efforts to focus on improving quality and not only quantity of care; 3 ) bolstering education and the internal research capacity within countries so that they can improve local evidence-based policy-making; 4) promoting intersectoral collaboration to achieve goals, and 5) improving collaborations between multilateral agencies - that are helping to monitor and evaluate progress towards the goals that are set - and the countries that are working to achieve improvements in health within their nation and across the world.

Keywords: Post-2015 Development Agenda, Millennium Development Goals (MDGs), Global Health, Information and Communication Technologies (ICT), Universal Health Coverage (UHC), Rwanda Copyright: @ 2015 by Kerman University of Medical Sciences

Citation: Binagwaho A, Scott KW. Improving the world's health through the post-2015 development agenda: Perspectives from Rwanda. Int J Health Policy Manag 2015; 4:203-205. doi: 10.15171/ijhpm.2015.46
\end{abstract}

\author{
Article History: \\ Received: 11 December 2014 \\ Accepted: 27 February 2015 \\ ePublished: 1 March 2015
}

A s the world enters this period of evaluation of the 2015 Millennium Development Goals (MDGs), it is useful to reflect upon the progress that has been made and the next steps we must collectively take to achieve a healthier future for all (1).

In Rwanda, a country of approximately 11 million people in East Africa, we can attest to the impetus that the MDGs have provided to mitigate unnecessary suffering, lower the mortality of children and mothers, and provide universal coverage for the prevention and treatment of HIV/AIDS, Tuberculosis (TB) and Malaria. Rwanda has embraced the challenge to measure progress and assess where it stands in relation to these goals. Fulfilling its national commitment to sustainable human development has required a collective and cohesive effort by Rwanda's policy-makers, including the social and financial sectors, and international collaborators, but the investment has paid off: Rwanda is on track to achieve the health-related goals for maternal and child health (MDGs 4 and 5) by $2015(2,3)$. The processes that have facilitated progress towards these goals - such as capacity building, infrastructure development, community engagement, a mindset shift and much more must continue to be developed. The targets for the post-2015 agenda cannot simply be the "end" in and of themselves - but rather the "means" for achieving better health and well-being for generations to come.

Drawing from Rwanda's experience to meet the healthrelated MDGs, we provide five guiding principles that we believe will help facilitate continued worldwide progress to improve health in a post-MDG era. Some may argue that Rwanda's small size, location, history and other characteristics make it too unique, limiting the generalizability of the lessons learned beyond its borders. However, we must not forget that Rwanda was considered by many to be a "lost cause" 20 years ago with its devastated economy and health system following the genocide (2). Thus, the lessons that Rwanda has learned while making such notable progress towards the MDGs, in spite of these challenges, may still be instructive for others to reflect upon as they determine the course they will take beyond 2015 .

First, we believe that the post-2015 goals should be driven by concrete and meaningful equity agendas. A pro-poor and pro-vulnerable agenda that extends beyond the traditional "health sector" to tackle the determinants of heath in a comprehensive manner must be fostered among policymakers and implementers. Rwanda has prioritized such an approach through its national policies, such as Vision 2020 and the Economic Development and Poverty Reduction Strategy $(4,5)$. A country cannot actually progress if only the "haves" witness the fruits of future investment while the "have nots" are further left behind. Such a mindset cannot be limited to national documents and visionary speeches, but in tangible, specific policy and action. For example, when Rwanda first created its community-based health insurance scheme (Mutuelles de Sante), the poorest million in the country were the first to receive free health insurance. Subsequently, Rwanda saw increased demand for insurance from those with higher incomes. By making insurance available to the broader population once this demand existed, this has helped create a pathway sustainable financing option for the Mutuelles program over time while ensuring that the poorest will 
continue to have free health insurance (6). These equity-driven approaches extend beyond the health sector. For instance, in terms of gender equity, Rwanda's Constitution commits to have at least $30 \%$ of leadership posts held by women. Today, Rwanda comes first in global rankings for women in Parliament; as of $2014,64 \%$ of parliamentary seats are held by women $(7,8)$.

The plight of the poor and vulnerable should be reflected upon in each context, requiring an honest assessment of who in society is disproportionately suffering unnecessarily and what can be done to resolve this. For example, Rwanda's traditional socio-economic assessment system (ubudehe) is the mechanism respected nationwide to identify the most vulnerable in a given community; national policies - such as Mutuelles - relies upon this system (2,9). As such, with the world looking towards laudable goals to "reduce poverty" in 2015 and beyond, targets to improve the lives of the worst off among us cannot be driven by a one-size-fits all approach.

Second, there has been much enthusiasm around the term "Universal Health Coverage" (UHC) as a post-2015 sustainable development goal (10). Many have looked towards Rwanda's Mutuelles program as a model for moving a country towards UHC (11). Yet there is a long way to go to sustain this momentum and assure that greater access translates into improved health outcomes. There is much work to be done in Rwanda, and worldwide, to improve the quality of health services to ensure they are more safe, effective and patientcentered so that UHC is a meaningful goal (12). Therefore, as Rwanda works towards improve the accessibility of its health services - in terms of geography, finances, gender and age - it must also continue to prioritize elevating the quality of these services.

Take Rwanda's healthcare workforce as an example. The country is still recovering from the health professional losses due to the genocide coupled with systemic health workforce shortages in the region. This prompted the development of the innovative Human Resources for Health (HRH) program a 7-year partnership with over 20 American universities to pair American specialists with Rwandan clinicians, dentists, nurses and health managers in training, to increase both the quantity and quality of Rwanda's health professional workforce (13). To enhance the quality of care delivered at healthcare facilities, Rwanda has been working with Joint Commission International to implement an accreditation program for the country's district, provincial and referral hospitals (14). Rwanda is also actively expanding innovations such as its nurse mentorship program (Mentoring and Enhanced Supervision at Health Centers) that has been shown to improve quality of care in rural settings to the country's HIV program (15).

Through these initiatives, Rwanda has recognized the need to measure and monitor dimensions of quality, and has leveraged its Health Management Information System (HMIS) to improve data collection on relevant measures (e.g. customer care, facility cleanliness). As such, others who are making strides to respond to the call for greater access to healthcare services through development goals such as UHC should consider how they can also assess, monitor, evaluate and improve the quality of such services.

Third, nations should carefully reflect upon the educational and research capacity within their own borders to study and monitor their own epidemiology and population health patterns, not only to meet the post-2015 development targets but also to improve evidence-based policy-making more broadly. This requires improved data information sources, enhanced capacity to manage and analyze data, a real commitment to enhancing Information and Communication Technologies (ICT) that will permit for improved data measurement, and much more. The United Nation's Global Digital He@lth Initiative (16) has made important contributions to demonstrate how bolstering tools, such as ICT, can play an instrumental role in meeting the post2015 development agenda. Rwanda has prioritized ICT growth nationwide and the health sector has benefited from these innovations (17). For example, Rwanda's RapidSMS ${ }^{\circledR}$ program, allows community health workers to input data on their phones, ranging from maternal deaths to signs of potential outbreaks, which is translated in real-time to officials responsible for the appropriate health response at the district and central levels $(18,19)$.

And while creating the technological infrastructure has been critical, strengthening the people who actually use these technologies is equally vital. This has been a motivating factor for why Rwanda's Ministry of Health has encouraged many its staff to pursue masters programs in public health or business administration to receive additional training that can bolster their managerial capacities, decision-making abilities and analytical toolkits. The world should be bold in setting an equitable, exciting, ambitious post-2015 agenda for comprehensive development, and this necessitates bold action to strengthen each country's own internal human capacity to study, monitor, manage, analyze and improve their population's health trends and needs. After all, a country's own people are best placed to be experts on their own burden of disease and know best how to strengthen the capacity to address these burdens.

Fourth, improving intersectoral collaboration within a country will greatly enhance the world's prospects to make substantive progress towards the post-2015 agenda. Each country should promote policies that foster synergies across sectors. The health sector cannot achieve health-related goals as an isolated, stand-alone system. For example, it needs the involvement of local leaders who govern by proximity and ensure the implementation of social policies, the transportation sector to build reliable roads that can reduce transit time for ambulances to reach hospitals, the communications sector to help promote the existence of new healthcare services, and so forth. The recent threat of ebola demonstrated the value of Rwanda's governance structures that harness synergies across sectors, such as the government's Social Cluster, and the importance of investing in health beyond the narrow health services sector $(2,20)$.

Fifth, it is important to improve collaborations between countries and the multilateral agencies that are charged with monitoring and evaluating the world's progress towards these post-2015 goals. This is likely the biggest area for why the future development targets in and of themselves should not be seen as the end, but rather a means for improving the value of work within countries so that all partners can work synergistically to meet the specific targets that are set, and any health challenges that may be on the horizon.

Improving collaboration between and across global health institutions may also help alleviate the tensions that countries, such as Rwanda, has faced when there have been 
discrepancies in published reports regarding its MDG-related progress (21). We must create tools and improve data quality produced by each country data so that projections made to demonstrate a nation's progress is relying on quality countrylevel data as opposed to distant estimates that are oftentimes based on fragile assumptions. To do so, countries need to play a much bigger role than they have in the past in generating high quality data. For instance, Rwanda's ongoing Demographic Health Survey (DHS), which is performed every 5 years, has benefited greatly from its collaboration with multilateral and bilateral development partners, and international nongovernmental organizations (22). The DHS monitors the status of population health and measures the impact of our programs, therefore informing country leadership alongside these external partners to see if it is on track to meet targets. These data collaborations also help motivate a collective planning process to overcome the challenges associated with the gaps that remain.

This also requires that development partners work inventively to remove the burdensome paperwork and report writing that seems to come alongside the well-intentioned but oftentimes overwhelming calls for measurement and documentation. With this, showcasing development progress to date has involved no shortage of international meetings and task forces, often requiring face-to-face sessions when telecommunication tools can help save precious time and resources. Real efforts to streamline the efforts to document or feature progress towards meeting the post-2015 agenda should be made as this will permit for more time to actually engage in quality service delivery.

In summary, as the world approaches the post-MDG era, it should consider the principles - such as these above - that have helped Rwanda achieve progress towards the health-related MDGs and continue to improve and build upon these efforts. Similarly, if a country fails to meet a particular target, it should assess the real reasons for why this is the case and then identify the infrastructure that is needed to meaningfully overcome these barriers. The targets - as laudable and motivating as they may be both prior to 2015 and in the post-MDG era - cannot be the end but the means for assuring progress. Ensuring that we are investing in people along the way as we take each step to make the world a better place is the end goal that matters most.

Ethical issues

Not applicable.

\section{Competing interests}

Authors declare that they have no competing interests.

\section{Authors' contributions}

Both authors contributed equally to the development and revision of this paper.

\section{Authors' affiliations}

${ }^{1}$ Minister of Health, Kigali, Rwanda. ${ }^{2}$ Harvard Medical School, Boston, MA, USA. ${ }^{3}$ Geisel School of Medicine, Dartmouth University, Hanover, NH, USA. ${ }^{4}$ Harvard University, Cambridge, MA, USA.

\section{References}

1. United Nations. United Nations Millennium Development Goals [Internet]. [cited 2015 Jan 10]. Available from: http://www.un.org/ millenniumgoals/beyond2015-overview.shtml

2. Binagwaho A, Farmer PE, Nsanzimana S, Karema C, Gasana M, de Dieu Ngirabega J, et al. Rwanda 20 years on: investing in life. Lancet 2014; 384: 371-5. doi: 10.1016/S0140-6736(14)60574-2
3. Farmer PE, Nutt CT, Wagner CM, Sekabaraga C, Nuthulaganti T, Weigel JL, et al. Reduced premature mortality in Rwanda: lessons from success. BMJ 2013; 346: f65. doi: 10.1136/bmj.f65

4. Government of Rwanda. Economic Development and Poverty Reduction Strategy (EDPRS2) [Internet]. 2013 [cited 2015 Jan 4]. Available from: http://www.edprs.rw/content/edprs-2

5. United Nations Rwanda. Economic Growth and Environment [Internet]. [cited 2014 Nov 25]. Available from: http://www.rw.one. un.org/what-we-do/inclusive-economic-transformation

6. Omaswa F, Crisp N. African Health Leaders: Making Change and Claiming the Future. Oxford University Press; 2014.

7. The World Bank. Gender Equality Data and Statistics - Rwanda [Internet]. [cited 2015 Jan 6]. Available from: http://databank. worldbank.org/data/Views/Reports/ReportWidgetCustom. aspx?Report_Name=GS_CN_1\&Id=64636f7e \&tb=y\&dd=n\&pr= $\mathrm{n} \& d w=y \& x|b|=y \& y|b|=y \& l e g e n d=y \& w d=420 \& h t=340 \&$ isportal $=y$ \&inf=n\&exptypes=Excel\&country=RWA

8. Inter-Parliamentary Union. Women in Parliaments: World Classification [Internet]. [cited 2014 Dec 29]. Available from: http://www.ipu.org/wmn-e/classif.htm

9. Rwanda Governance Board. Ubudehe [Internet]. [cited 2015 Feb 24]. Available from: http://www.rgb.rw/governance-innovations/ ubudehe/

10. Vega J. Universal health coverage: the post-2015 development agenda. Lancet 2013; 381: 179-80. doi: 10.1016/s01406736(13)60062-8

11. Musangoi L, Makakaii A, Muhongerwaiii D, Kalisaiv IR, Elovainiov R. Strategies towards universal health coverage in Rwanda: lessons learned from extending coverage through mutual health organizations [Internet]. Afr Health Obs [cited 2015 Feb 25]. Available from: http://www.aho.afro.who.int/pt-pt/ahm/issue/17/ reports/strategies-towards-universal-health-coverage-rwandalessons-learned-extending

12. Scott KW, Jha AK. Putting Quality on the Global Health Agenda. N Engl J Med 2014; 371: 3-5. doi: 10.1056/nejmp1402157

13. Binagwaho $A$, Kyamanywa $P$, Farmer $P E$, Nuthulaganti $T$, Umubyeyi B, Nyemazi JP, et al. The Human Resources for Health Program in Rwanda - A New Partnership. N Engl J Med 2013; 369: 2054-9. doi: 10.1056/NEJMsr1302176

14. Mbonyinshuti JD. Public hospitals urged to work hard to earn international accreditation [Internet]. New Times Rwanda [cited 2015 Jan 5]. Available from: http://www.newtimes.co.rw/section/ article/2014-10-06/181651/

15. Anatole M, Magge $H$, Redditt V, Karamaga A, Niyonzima S, Drobac $P$, et al. Nurse mentorship to improve the quality of health care delivery in rural Rwanda. Nurs Outlook 2013; 61:137-44. doi: 10.1016/j.outlook.2012.10.003

16. United Nations. Vision \& Mission for the Digital He@Ith Initiative [Internet]. [cited 2014 Dec 11]. Available from: http://www.un.org/ partnerships/Docs/DHI\%20Vision\%20\&\%20Mission.pdf

17. Ben-Ari N. Big dreams for Rwanda's ICT sector - Africa Renewal Online [Internet]. [cited 2015 Jan 15]. Available from: http:// www.un.org/africarenewal/magazine/april-2014/big-dreamsrwanda\%E2\%80\%99s-ict-sector

18. Binagwaho A, Nyatanyi T, Nutt CT, Wagner CM. Disease outbreaks: Support for a cholera vaccine stockpile. Nature 2012; 487: 39. doi: 10.1038/487039c

19. Ngabo F, Nguimfack J, Nwaigwe F, Mugeni C, Muhoza D, Wilson DR, et al. Designing and Implementing an Innovative SMSbased alert system (RapidSMS-MCH) to monitor pregnancy and reduce maternal and child deaths in Rwanda. Pan Afr Med $J$ 2012;13: 31.

20. Binagwaho A. Preparation Is Paramount. Finance Dev 2014; 51: 33.

21. Binagwaho A, Ngabo F, Mugeni C, et al. Discrepant estimates of key indicators for Millennium Development Goals 4 and 5: the public sector's experience in Rwanda. Lancet 17; 381: S16. doi: 10.1016/s0140-6736(13)61270-2

22. National Institute of Statistics of Rwanda. Demographic and Health Survey (DHS) [Internet]. [cited 2015 Jan 10]. Available from: http://www.statistics.gov.rw/survey/demographic-andhealth-survey-dhs 